\title{
Ethical Basis of Professionalism
}

\author{
Vladimir Tsvyk \\ Faculty of Humanities and Social Sciences \\ Peoples' Friendship University of Russia \\ Miklukho-Maklaya str., 10/2, Moscow, Russia, 117198 \\ E-mail: tsvyk_va@rudn.university
}

\author{
Vinera Mukhametzhanova \\ Faculty of Humanities and Social Sciences \\ Peoples' Friendship University of Russia \\ Miklukho-Maklaya str., 10/2, Moscow, Russia, 117198 \\ E-mail: mukhametzhanova_vs@rudn.university
}

\begin{abstract}
The article examines the ethical basis of professionalism as one of the most important characteristics of personal development. According to the authors' opinion it is professionalism that ensures the individual's ability of productive, creative work. The authors analyze correspondence between the concepts "professionalism" and "professional" and give axiological and acmeological understanding of professionalism. A phenomenon of professionalism in the history of mankind extended following the sophistication of the social structure, when new conditions for the one's self-actualization were arising and one's attitude to labor and its components were changing. The historical path traversed by the concept of professionalism resulted in the fact that nowadays it is a multi-aspect phenomenon. Nowadays the individual's ethical values and priorities that allow one to choose the optimal format for professional duties execution, along with the corresponding knowledge, skills and abilities, become the basis of professionalism.
\end{abstract}

Keywords-ethics; professional ethics; professional activity; professionalism; professional

\section{INTRODUCTION}

Drastic changes in the development of mankind and the growth of human agency at the beginning of the 21 st century led to a manifold increase of the man's impact on the world around him. The consequences of this impact are manifested in nature, society, person's life, that is, acquire a global character. In modern society professionalism becomes the most important characteristic of a person qualifying his/her capabilities in that kind of activity, to which person devoted his entire working life. Today the phenomenon of professionalism raises the close interest not only of researchers in the field of social problems, but also of ethics, as the moral component of professionalism becomes increasingly evident [1. P. 136].

\section{CONCEPTS "PROFESSIONAL" AND "PROFESSIONALISM"}

On the one hand, the widely used term "professionalism" is axiologically neutral and does not imply the moral aspect. The term "professional" is defined in the explanatory dictionary as "a person who has turned some occupation his permanent profession". In the sociological dictionary, the term "professional" is interpreted as follows: a professional is "an individual whose main occupation is his/her profession; specialist in the field, appropriately trained and qualified." Accordingly, "professionalism" is understood as the degree of mastering by an individual certain professional skills, hence in the literature, and in the ordinary perception, such characteristics of the individual as "high professionalism" and "low professionalism" are common.

At the same time, in the modern domestic literature there prevails a different, broader interpretation of the terms "professional" and "professionalism". Professionalism is most often understood as the aggregate of theoretical knowledge, practical experience and professional skills achieved by an individual in a specific, determined by the division of labor and professional specialization sphere of human activity. Thus, professionalism is not only the source of human existence and manifestation of personal potential, but also a decisive factor for development of civilization, formation of humane and fair social relationship, establishment in society of such principle as diligence, raise of the moral value of labor and creative work. Therefore, professionalism, despite the seeming "moral neutrality", is closely related to the person's morality.

The moral content of a person, his ability to exercise the right moral choice, maturity of his understanding of such notions as honor, duty and responsibility largely determine successfullness of his/her professional activity. Only a harmoniously developed person, steadily improving not only his own professional skills, but also his moral consciousness, who is guided in professional activity by humanistic moral principles, is able to become a true professional.

\section{THE CONCEPT OF PROFESSIONALISM}

It should be noted that, unlike Western authors, who interpret professionalism mainly as a clearly fixed qualification of a high level, modern domestic researchers tend to see in this concept a clearly expressed axiological aspect. Professionalism in modern domestic literature is interpreted precisely as an axiologically meaningful quality of an individual, or less often - as a quality of the professional activity itself.

Quite often in the research literature the term "professionalism" is identified with the activity itself, it is interpreted as its kind, requiring certain abilities, knowledge, skills. The activity approach to the concept of professionalism is also revealed in the book of G.V. Lazutina, who righteously notes that a developed society knows two forms of human activity: amateurism and professionalism. Every activity starts as amateur, amateurism is the first phase 
of development of activity and the initial form of its organization. Specificity of amateur activity is that it is carried out by a person on personal inclination, outside the scope of any official duties, without special training and without strict responsibility for the result. Professional activity is formed on the basis of the amateur, but does not absorb it, both forms continue to exist in parallel. Having become the new kind of occupation for a person, professional activity acquires new features: it proceeds in the form of execution of the corresponding official duties, implies responsibility for the result, requires special training, i.e. turns into a profession [2. P. 65]. Let's add that the important aspect of the conversion of the amateur activity into a professional one is the moral attitude of the person to it, his responsibility for the quality of product (material or intellectual). Thus, professionalism becomes an ethical requirement, and the formation of professional consciousness implies the inclusion in its structure of ethical norms.

In the works of Russian vocationalists the emphasis is placed on the axiological aspect of professionalism, which is interpreted as the quality of a person or less often as a quality of the professional activity itself. In the modern economic dictionary the professionalism is explained as a high skill, profound mastery of the profession, high-quality professional performance. Within the psychological approach to this problem, professionalism is considered primarily through the prism of psychophysiological and functional-psychological qualities of an individual. So, E. A. Klimov's concept of professionalism is a special psychological state of a person: "we will understand professionalism not simply as a new higher level of knowledge and human results in a specific field of activity, but as a definite systemic organization of consciousness, the psyche of a man ..." [3. P. 10].

The phenomenon of professionalism is also comprehensively studied in the framework of actively developing in recent years in our country acmeology as a science about the conditions and factors that ensure the highest level of achievements in any activity. Obviously, with regard to professional activity, such level is called professionalism. In this context, many authors consider professionalism as the quality of professional activity determined by personal abilities: "Professionalism is the highest standard of professional activity, characterizing the personal capabilities of the performer, his freedom to choose the most convenient and appropriate mode of activity. The professionalism is built on higher qualification, skills and goal-setting" [4. P. 46]. In the framework of this approach, which, in our opinion, can be characterized as evaluative, or acmeological, professionalism emphasizes the quality of the individual as the performer in a certain area of socially useful activity.

Professionalism reflects changes in skills, abilities, qualifications in terms of demands imposed on the individual by his profession in accordance with the scientific, technical and intellectual development of society. The essence of professionalism is the professional advancement from choosing a profession to mastering it, achieving professional mastery, creative success. As a personal trait, it is defined as individual's sensible attitude and behavior in relation to his work activity throughout the life, his actualized to varying degrees abilities as a specialist, and, finally, public recognition and a certain esteem expressed in the social position. However, it is not enough to define modern professionalism only as high level professional skills. The moral value of labor, postulated in different cultures and different epochs and reflected in numerous oral and written sources, in our view, demonstrates the necessity to include in the subject matter of this concept meaning-of-life, noetic and moral characteristics.

Thus, in order to complement and expand the wellknown characteristic of professionalism as the personal quality, we should note that professionalism necessarily implies the concord between the psychological and ideological readiness of the individual for successful professional implementation and the level of social (including moral) requirements for this profession. Professionalism is the correspondence of knowledge, skills, abilities, as well as the whole person's system of values with what is happening in a specific field of professional activity. In other words, professionalism is the correspondence of a wide range of person's qualities (skills, abilities, knowledge, values, ideals) with the level of public expectations of certain profession [5. P. 65].

\section{Professionalism as a MoRAl VAlue}

Since the public expectations and demands made by society towards the profession are subject to change in accordance with the scientific, technical, intellectual and social development of the society itself - the phenomenon of professionalism is historically mobile: the subject matter of this concept is expanding in accordance with social development, complexity of the social structure and advent of new conditions for the person's self-actualization in the society.

Having originated in the process of professional differentiation of human labor, professionalism as a person's ability to perform an expedient activity transforming the objective world was originally narrowly understood as the possession of a certain skill set. The historical industrial development, growing dynamics of professional activity, sophistication and enhancement of social relations led to the fact, that in the 20th century, the necessary condition for professionalism is considered to be the creative attitude of a person to the profession, his ability to realize in his professional activity all his essential forces. At the present time, during the process of transition to postindustrial world, in connection with the actualization of humanistic values and, correspondingly, the raising of public requirements for many professions, the concept of "professionalism" is substantially expanding. Its subject matter, along with practical skills and abilities, necessary implies a broad worldview, worldly and social awareness and universal human moral values. The core of the professional's personality in modern sense is his worldview in conjunction with the ideological, moral, philosophical and socio-psychological aspects. Moreover, the value of a person's worldview can not be limited only by the sum of accumulated knowledge. It also represents the 
creativity of a human being, its ability to use knowledge professionally.

Professionalism has an important moral value in modern society also because the effective professional performance is impossible today without high spiritual and moral characteristics of the performer. The moral essence of an individual is being embodied in things produced through skill, which, in turn, is closely related to a sense of dignity. The higher the professional skill of the employee, the more strongly he develops a sense of dignity, professional pride. Genuine professionalism also implies the responsibility of the employee. Thus, as a moral imperative, professionalism turns out to be included in the list of professional and ethical categories, which concretize general ethical concepts in relation to one's professional activities: duty - professional duty, conscience - professional conscience, responsibility professional responsibility, pride - professional pride etc. At the same time, the "professionalism" category takes a special place in the structure of professional ethics by right. Professional activities associated with certain working conditions leaves its imprint on the people's moral and psychological properties. So, not being essentially an ethical category, the concept of "professionalism" has broad social and moral contents. The requirement of professionalism becomes one of the main normative provisions in many professional and ethical codes of modern society.

The concept of "professionalism" is a kind of generalization of specific professional and ethical norms. Indeed, professionalism presupposes the presence of professional conscience and awareness of professional duty, moral responsibility for the results of professional work and a sense of professional dignity and pride. In turn, "moral motives are effective only when they are backed by professional knowledge, skills and abilities" [6. P. 43]. Thus, professionalism implies adherence to both professional morality and general moral norms and well-developed professional and moral consciousness of the individual. This is the ethical aspect of professionalism, its moral value.

Moral orientation of the individual in the process of professionalization means mutual responsibility, loyalty, tolerance, decency, cooperation. Without observing these elementary principles it is impossible to find freedom in creativity and self-realization of oneself as individuality [7. P. 85].

\section{CONCLUSION}

You can endlessly list the qualities needed by a modern specialist in order to become a professional. Increasingly, we are talking about computer literacy, without which today it is impossible to fit into the information flow, the need for knowledge of foreign languages, "professional flexibility", breadth of mental outlook [8. P. 132]. However, one of the most important characteristics of modern professionalism is his moral imperative.

A modern professional must possess not only a certain amount of professional knowledge and skills, but also a developed professional and moral consciousness, which includes a sense of professional duty, professional conscience, professional dignity. Professionalism requires the ability to anticipate the consequences of professional activity, to bear personal responsibility for them.

From the ethical point of view, professionalism means the ability to harmonize professional activity with moral standards and act properly in any professional situations.

\section{REFERENCES}

[1] Mukhametzhanova V. S. Moral-ethical aspect of professionalism // Bulletin of The Peoples' Friendship University of Russia. The Philosophy Series. - 2013. - No. 3. - S. 135-142.

[2] Lazutina G. V. Professional ethics of a journalist. - M.: Aspect Press, 2000.

[3] Klimov E. A. Professional psychology. - M., 1996.

[4] Zazykin V. G., Chernyshev A. P. Acmeological problems of professionalism. - M., 1993.

[5] Tsvyk V. A. Professional ethics: foundations of the general theory. M., 2010.

[6] Kapto A. S. Professional ethics. - M. - Rostov-on-Don: NCAPS publishing house, 2006.

[7] Aliyeva O. G., Savvina O. V., Moiseenko M. V. Crisis of national cultures in the era of globalization // Bulletin of The Peoples' Friendship University of Russia. The Philosophy Series. - 2014. - No. 2. - P. 83-91.

[8] I. Tsvyk V. Computer ethics and the intellectual security // Bulletin of The Peoples' Friendship University of Russia. The Philosophy Series. - 2013. - No. 3. P. 125-135. 